\title{
ZVZCS PWM DC-DC CONVERTER WITH CONTROLLED SECONDARY RECTIFIER FOR ARC WELDING
}

\author{
Jaroslav DUDRIK, Marek PÁSTOR, Milan LACKO, Róbert ŽATKOVIČ \\ Department of Electrical Engineering and Mechatronics, Faculty of Electrical Engineering and Informatics, \\ Technical University of Košice, Letná 9, 04200 Košice, Slovak Republic, Tel.: +421 55602 2276, Ë-mail: jaroslav.dudrik@tuke.sk
}

\begin{abstract}
A zero-voltage, zero-current switching (ZVZCS) PWM DC-DC power converter with secondary active rectifier tested as a dc current source for arc welding is described in this paper. The soft switching DC-DC converter consists of high frequency inverter, high frequency power transformer and controlled output rectifier with new secondary energy recovery turn-off snubber. Circulating current in the converter is reduced by using active rectifier and rms value of the current in secondary switches is decreased by utilizing a novel control algorithm. The experimental results of a $4.5 \mathrm{~kW} \mathrm{DC-DC} \mathrm{converter} \mathrm{working} \mathrm{at} \mathrm{switching} \mathrm{frequency} \mathrm{of} 100$ $\mathrm{kHz}$ are presented.
\end{abstract}

Keywords: DC-DC converter, zero-voltage switching (ZVS), zero-current switching (ZCS), arc welding

\section{INTRODUCTION}

Generally, voltage-current characteristics of the arc welder depend generally on the type of welding. Typical rated voltage is about $50-80 \mathrm{~V}$ and the rated current falls within the range $60 \mathrm{~A}$ up to $1000 \mathrm{~A}$.

Modern welders are required to have many features like reliability, safety, lightness, robustness, flexibility of operation, high efficiency, wide current control range, good power factor, electrically isolated output, fast response, fault tolerance, good price, adaptation to various operating conditions and so on [1] - [2].

In the quest for smaller size and lighter weight of the power source it is necessary to operate the inverter at as high switching frequency as possible. This high frequency allows considerably reducing the size and weight of the transformer and it makes the filtering at the dc output of the DC-DC converter easier and cheaper. Moreover, it allows using a physically small inductor to reduce the output current ripple to very low values. However, higher switching frequency results in increased switching losses in power semiconductor devices at turn-on and turn-off.

All these requirements can be easily met by welders consisting of a high frequency transformer fed by highfrequency soft-switching converter.

There are various types of dc-dc converters for arc welders. All of the converters have certain pros and cons. Resonant converters working below or above resonance frequency are often used for construction of electronic welders. Utilizing resonant components, however, introduces additional circulating energy in the converter circuits. This circulating energy increases voltage or current stress of the semiconductor devices and converter passive components often show increased conduction losses [3] - [5]. Moreover, the switching frequency range is often limited so that the converters would not lose the soft switching. Almost the same holds for other types of resonant converters e.g. quasi-resonant converters [6], [7], multiresonant converters [8] - [9], and so on. Moreover, the frequency modulation, mostly used for controlling these converters, is disadvantageous due to EMI suppressing.
The other possibility is to use PWM converters. The circulating energy is minimum compared with the resonant converters resulting in minimum conduction losses. These converters are controlled either by traditional PWM or by phase shifted PWM method at constant switching frequency. The semiconductor devices in conventional PWM power converters suffer from high switching losses. However, by introducing the auxiliary circuits and proper control modes, zero-voltage and/or zero-current switching can be achieved [10] - [12]. Several types of dissipative, non-dissipative and energy recovery more or less complex snubbers, clamps and auxiliary circuits were developed to resolve the problem of reducing the switching losses [10] - [12] and circulating currents [10] - [12].

Using an active output rectifier in the secondary side of the converter is another very effective way, how to decrease circulating currents in the PWM converters and, at the time, to achieve reduction of switching losses [13] [19].

ZVZCS PWM DC-DC high power converter with active rectifier on the secondary side used as a current source is presented in this paper. The paper is linked to article [19], where the principle of the converter working as a voltage source is explained and basic equations for rated load are derived. The application and control features of the converter operating as a current source are presented here. Moreover, the converter analysis, presented in [19] for rated load, is extended also for light load in this paper. This is important for the converters operating at full load range - from no-load to short circuit, e. g. at converters for arc welding.

\section{CONVERTER OPERATION}

\subsection{Power circuits}

Power circuit of the converter is shown in Fig. 1. The input voltage is converted by a full-bridge high frequency inverter (IGBT transistors $T_{1}-T_{4}$ and freewheeling diodes $D_{1}-D_{4}$ ) to the high frequency alternating voltage across primary winding of the high frequency step-down 


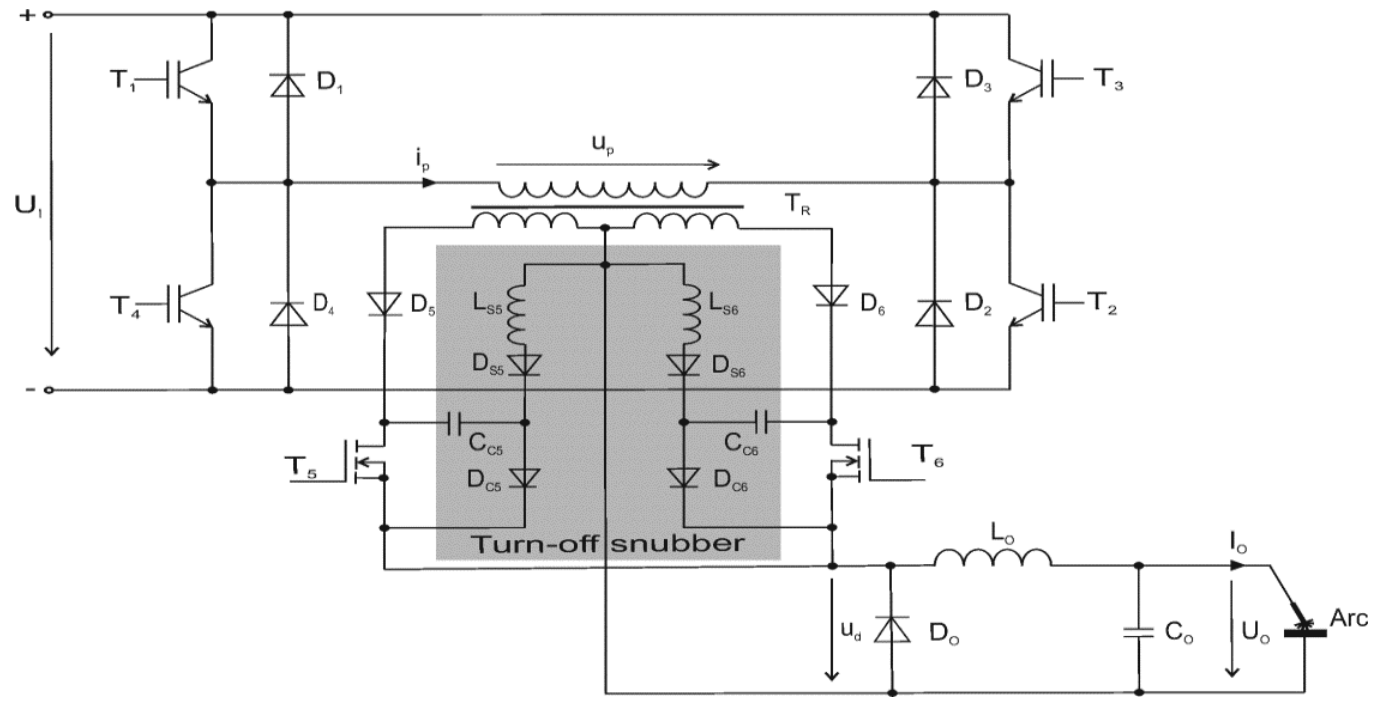

Fig. 1 ZVZCS PWM DC-DC power converter

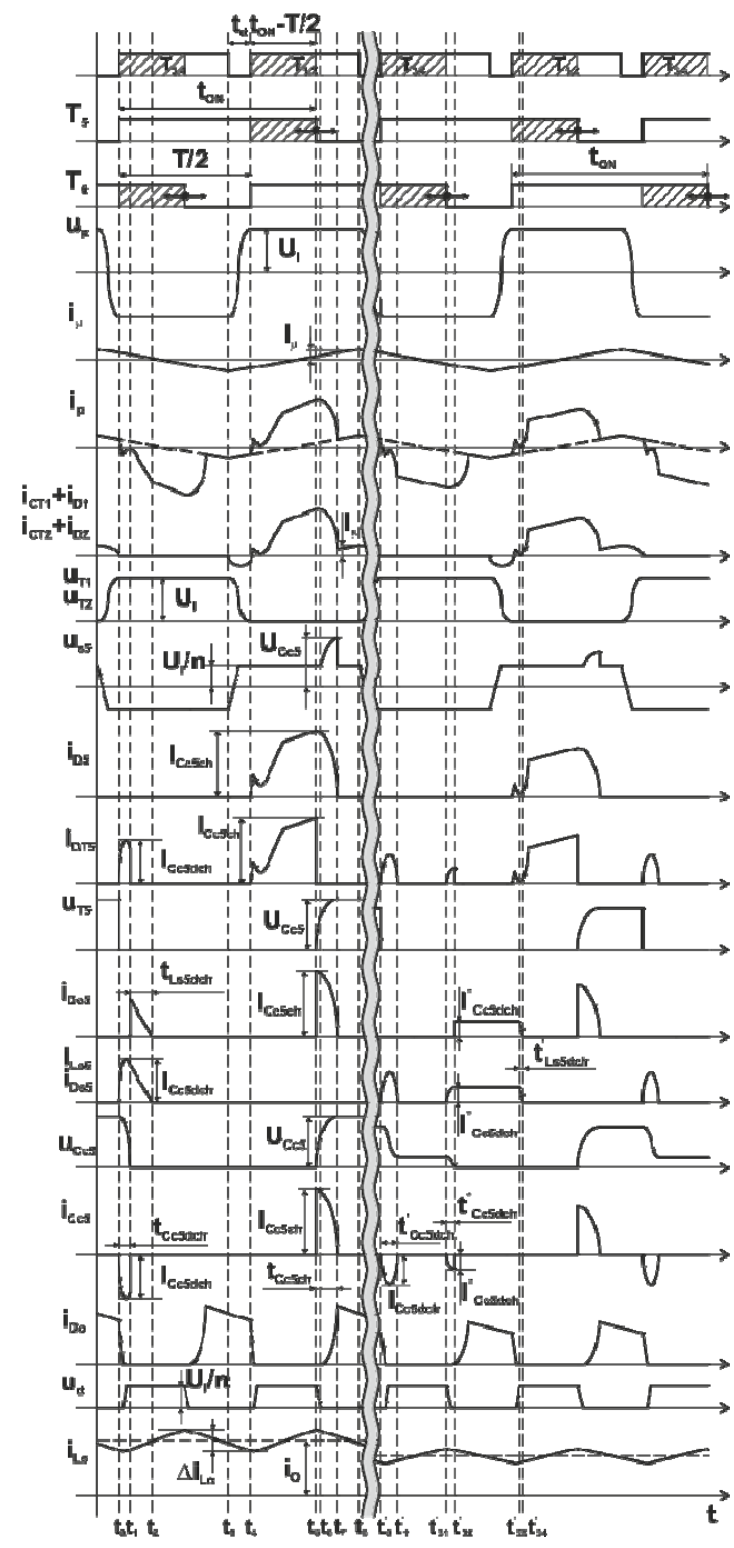

Fig. 2 Converter waveforms for rated load (left side) and light load (right side) transformer $T_{R}$. The secondary center-tapped winding of this transformer is connected through an active rectifier between the welding rod and the material to be welded. The controlled rectifier consists of a series connection of MOSFET transistors $T_{5}, T_{6}$ and fast recovery diodes $D_{5}$, $D_{6}$.

Behaviour of this type converter is the result of a new way of controlling (Fig. 2, Fig. 3). Full-bridge inverter $T_{1}$ $-T_{4}$ is controlled with constant switching frequency and $50 \%$ duty cycle. Value of the output current is controlled via pulse-width modulation of the secondary switches $T_{5}$, $T_{6}$.

The commutation of the freewheeling diodes to transistors in high frequency inverter is soft, without large reverse recovery current spikes. So, there are not high requirements on the freewheeling diode dynamic properties. The transistors of the inverter are turned-on under zero-voltage and zero-current, and so the turn-on losses are negligible. Turn-off losses of the primary transistors are negligible as well. They turn off only a small magnetizing current of the power transformer.

To reduce turn-off losses of secondary switches $T_{5}, T_{6}$, and accumulation of leakage energy of the power transformer the new turn-off snubber was designed [17], consisting of snubber capacitors $C_{C 5}, C_{C 6}$, snubber inductors $\mathrm{L}_{\mathrm{S} 5}$, and $\mathrm{L}_{\mathrm{S} 6}$ and snubber diodes. From the point of view of efficiency the non-dissipative snubbers are the most promising ones. Therefore, in the suggested solution used is this option - see Fig. 1.

Leakage inductance of the transformer acts as a turn on snubber for secondary switches. Therefore, zero current turn-on is achieved.

Snubber capacitors $\mathrm{C}_{\mathrm{C} 5}$, and $\mathrm{C}_{\mathrm{C} 6}$ reduce the rate of rise of the drain-source voltage of secondary transistors $T_{5}$, and $T_{6}$ and thus zero voltage turn off is ensured [18], [19].

Beside reducing turn off losses in secondary switches the snubber capacitors $C_{C 5}, C_{C 6}$ ensure also accumulation of the leakage inductance energy of the power transformer and consequently its transfer through snubber inductors $L_{S 5}, L_{S 6}$ and diodes $D_{S 5}, D_{S 6}$ to the load. 


\subsection{Operation at light load}

As was mentioned above, operation principle of this converter at rated load (Fig. 2 - left side) is described in detail in [19].

In this paper, the description of the proposed converter is focused on conditions at light load.

Contrary to the rated load, discharging of the snubber capacitor (voltage $U_{C C 5}$ ) at light load runs in two intervals: $\mathrm{t}^{\prime}{ }_{0}-\mathrm{t}_{1}{ }_{1}$ and $\mathrm{t}_{31}{ }_{31}-\mathrm{t}^{\prime}{ }_{32}$ (right side of the Fig. 2), respectively.

Operation of the proposed converter at light load is analyzed in the below section. The basic light load operation of the proposed soft switching converter has four operating modes within each half cycle. Because of the leg symmetry, the transistors $T_{1}, T_{2}$ and $T_{3}, T_{4}$ work under the same operating conditions. Operation of the secondary switches is also symmetrical. It is assumed that all components and devices are ideal.

\section{Interval $\left(t_{0}^{\prime}-t_{1}^{\prime}\right)$ :}

Secondary transistor $\mathrm{T}_{5}$ is turned on at $\mathrm{t}_{0}{ }_{0}$ half period earlier then primary transistors $T_{1}$ and $T_{2}$. Capacitor $C_{C 5}$ starts discharging through $\mathrm{T}_{5}, \mathrm{~L}_{\mathrm{O}}, \mathrm{R}_{\mathrm{O}}, \mathrm{L}_{\mathrm{S} 5}$, and $\mathrm{D}_{\mathrm{S} 5}$ (Fig. 3a).

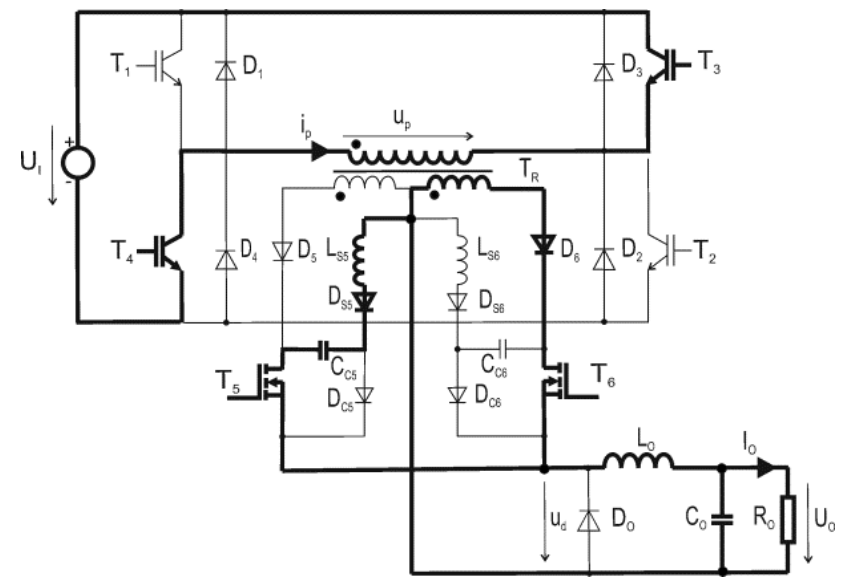

Fig. 3a Operation in interval $\mathrm{t}^{\prime}{ }_{0}-\mathrm{t}^{\prime}{ }_{1}$

Current and voltage of capacitor $C_{C 5}$ can be, for the discharging process, calculated from the following equations

$$
\begin{aligned}
& i_{C c 5}(t)=\sqrt{\frac{C_{C 5}}{L_{S 5}}}\left(\frac{U_{I}}{n}-U_{C c 5}\right) \sin \left(\frac{t-t_{0}}{\sqrt{L_{S 5} C_{C 5}}}\right) \\
& u_{C c 5}(t)=\frac{U_{I}}{n}+\left(U_{C c 5}-\frac{U_{I}}{n}\right) \cos \left(\frac{t-t_{0}}{\sqrt{L_{S 5} C_{C 5}}}\right)
\end{aligned}
$$

where $n=u_{p} / u_{s}=n_{p} / n_{s}$ is transformer turns' ratio.

If the initial voltage of snubber capacitor $C_{C 5}$ is smaller than double rectified voltage

$U_{C c 5}<2 \frac{U_{I}}{n}$ then the snubber capacitor keeps discharging until capacitor voltage $\mathrm{u}_{\mathrm{Cc5}}(2)$ reaches minimum

$u_{C c 5\left(t_{1}^{\prime}\right)}=\frac{U_{I}}{n}+\left(U_{C c 5}-\frac{U_{I}}{n}\right)(-1)=2 \frac{U_{I}}{n}-U_{C c 5}$

The discharging time is

$t_{C C 5 d c h}^{\prime}=t_{1}^{\prime}-t_{0}^{\prime}=\pi \sqrt{L_{S 5} C_{C 5}}$ (1)

Magnitude of the discharging current is derived from

$I_{C c 5 d c h}=\left|\sqrt{\frac{C_{C 5}}{L_{S 5}}}\left(\frac{U_{I}}{n}-U_{C c 5}\right)\right|=\sqrt{\frac{C_{C 5}}{L_{S 5}}}\left(U_{C c 5}-\frac{U_{I}}{n}\right)$

Borderline between rated load and light load is determined by the condition (3). Light load of the converter starts when condition (3) is met.

\section{Interval $t_{31}^{\prime}-t^{\prime}{ }_{32}$}

Total discharging of snubber capacitor $\mathrm{C}_{\mathrm{C} 5}$ occurs in this interval if condition (3) is met.

In $\mathrm{t}^{\prime}{ }_{31}$ before secondary transistor $\mathrm{T}_{6}$ turning off, commutation occurs and output freewheeling diode $\mathrm{D}_{\mathrm{O}}$ starts to lead the current. Rectified voltage ud drops to zero, and therefore total discharging of the snubber capacitor $\mathrm{C}_{\mathrm{C} 5}$ is enabled.

At the same time the leakage inductance energy of the transformer is absorbed by snubber capacitor $\mathrm{C}_{\mathrm{C} 6}$.

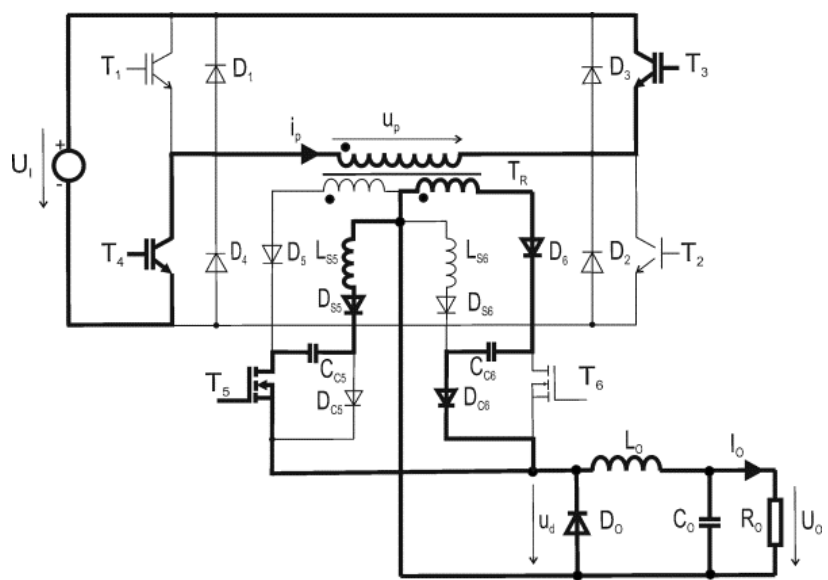

Fig. 3b Operation in interval $\mathrm{t}^{\prime}{ }_{31}-\mathrm{t}^{\prime}{ }_{32}$

Value of the snubber capacitor voltage at $t^{\prime}{ }_{31}$ is derived from (4).

$u_{C c 5\left(t_{31}^{\prime}\right)}=u_{C c 5\left(t_{1}^{\prime}\right)}=2 \frac{U_{I}}{n}-U_{C c 5}$

Then snubber capacitor $C_{C 5}$ voltage and current time waveforms are as follows 
$i_{C c 5}(t)=\left(U_{C c 5}-2 \frac{U_{I}}{n}\right) \sqrt{\frac{C_{C 5}}{L_{S 5}}} \sin \left(\frac{t-t_{31}^{\prime}}{\sqrt{L_{S 5} C_{C 5}}}\right)$

$u_{C c 5}(t)=\left(2 \frac{U_{I}}{n}-U_{C c 5}\right) \cos \left(\frac{t-t_{31}^{\prime}}{\sqrt{L_{S 5} C_{C 5}}}\right)$

Snubber capacitor discharging lasts a quarter period of resonance between snubber capacitor $C_{C 5}$ and snubber inductance $L_{S 5}$ i.e. until snubber capacitor voltage reaches zero.

Capacitor discharging time can be derived from (9) as follows

$t_{C c 5 d c h}^{\prime \prime}=t_{32}^{\prime}-t_{31}^{\prime}=\frac{\pi}{2} \sqrt{L_{S 5} C_{C 5}}$

The following equation holds for amplitude of the capacitor current

$I_{C c 5 d c h}^{n}=\left|\sqrt{\frac{C_{C 5}}{L_{S 5}}}\left(U_{C c 5}-2 \frac{U_{I}}{n}\right)\right|=\sqrt{\frac{C_{C 5}}{L_{S 5}}}\left(2 \frac{U_{I}}{n}-U_{C c 5}\right)$

Interval $t_{32}^{\prime}-t_{33}^{\prime}$

At the beginning of this interval the current of snubber capacitor $C_{C 5}$ commutates to snubber diode $D_{C 5}$. At the same time current of snubber inductor $\mathrm{L}_{\mathrm{S} 5}$ decays through diode $D_{C 5}$.

Since within this interval the rectified voltage is zero, the snubber inductor current is maintained constant. Simultaneously, the leakage inductance energy of the transformer is stored in opposite snubber capacitor $C_{C 6}$ during this interval.

Directions of the currents at the beginning of this interval are shown in Fig. 3c.

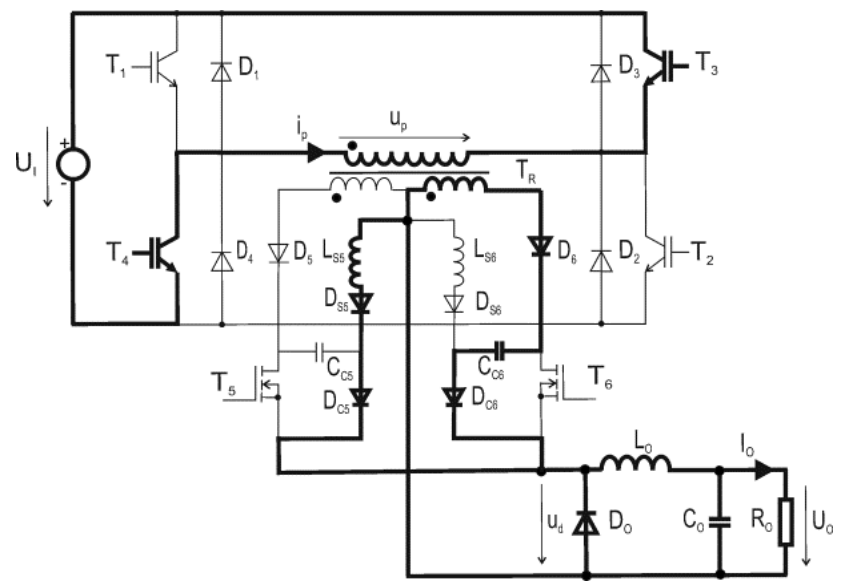

Fig. 3c Operation in interval $t^{\prime}{ }_{32}-t^{\prime}{ }_{33}$

Value of the inductor current $i_{\text {Ls } 5}$ is equal amplitude of the snubber capacitor $C_{C 5}$ discharging current

$i_{L s 5\left(t_{32}^{\prime}\right)}=I_{C c 5 d c h}^{\prime \prime}=\sqrt{\frac{C_{C 5}}{L_{S 5}}}\left(2 \frac{U_{I}}{n}-U_{C c 5}\right)=$ const.
Interval $t_{33}^{\prime}-t_{34}^{\prime}$

After turn on of inverter transistors $T_{1}, T_{2}$ the rectified voltage $u_{d}$ is increased to value of $U_{I} / n$ and energy of snubber inductor $L_{S 5}$ is transferred to the load.

At the same time the energy is transferred from primary side through transistors $T_{1}, T_{2}, T_{5}$ and diode $D_{5}$ to the load.

Simultaneously snubber capacitor $C_{C 6}$ is discharging in a resonant way to the load through opposite secondary transistor $T_{6}$ (Fig. 3d).

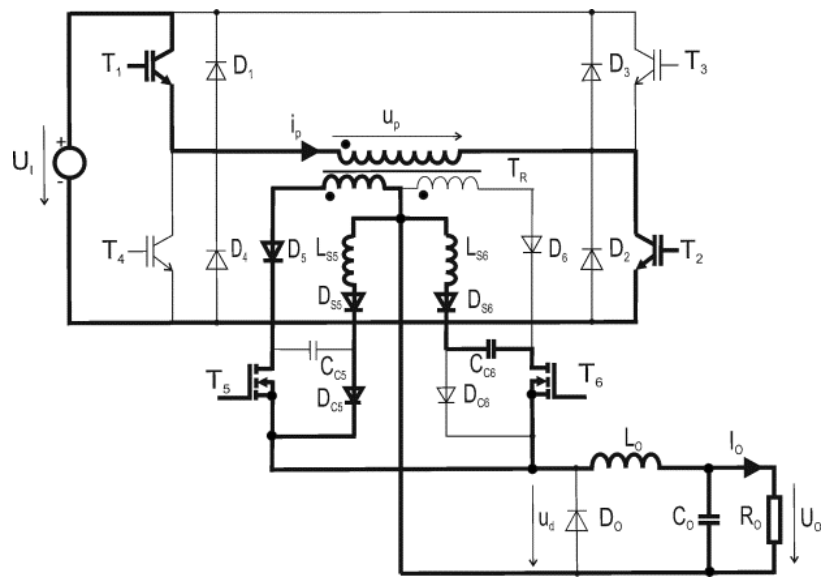

Fig. 3d Operation in interval $t^{\prime}{ }_{33}-t^{\prime}{ }_{34}$

Value of the rectified voltage is

$u_{d\left(t_{33}^{\prime}\right)}=\frac{U_{I}}{n}$

Value of the snubber inductor current $i_{L s 5}$ at the beginning of this interval is given by

$i_{L s 5\left(t_{33}^{\prime}\right)}=i_{L s 5\left(t_{32}^{\prime}\right)}=I_{C c 5 d c h}^{\prime \prime}=\sqrt{\frac{C_{C 5}}{L_{S 5}}}\left(2 \frac{U_{I}}{n}-U_{C c 5}\right)$

For time dependency of the snubber inductor current $\mathrm{i}_{\text {Ls5 }}$ the following expression holds

$i_{L s 5}(t)=\sqrt{\frac{C_{C 5}}{L_{S 5}}}\left(2 \frac{U_{I}}{n}-U_{C c 5}\right)-\frac{U_{I}}{n} \frac{t-t_{33}^{\prime}}{L_{S 5}}$

Decay time $t_{\text {Ls5dch }}^{\prime}$ of the snubber inductor current $i_{\text {Ls5 }}$ can be determined from

$t_{L s 5 d c h}^{\prime}=t_{34}^{\prime}-t_{33}^{\prime}=\frac{\sqrt{\frac{C_{C 5}}{L_{S 5}}}\left(2 \frac{U_{I}}{n}-U_{C c 5}\right)}{\frac{U_{I}}{n}} L_{S 5}$

\section{CONTROL CIRCUITS}

The converter is controlled by novel pulse-width modulation of secondary transistors. The pulse length is changed from $t_{\mathrm{ON} \text { (MIN) }}$ to $\mathrm{t}_{\mathrm{ON}(\mathrm{MAX})}$, which means ca. from $\mathrm{T} / 2$ to $\mathrm{T}$, if disregarded are the dead time and capacitor 
charging time (precisely from $\left(T / 2-t_{d}\right)$ to $\left(T-t_{d}-\right.$ $\left.t_{\mathrm{Cc} 5 \mathrm{ch}(\mathrm{MAX})}\right)$ as shown in Fig. 4).

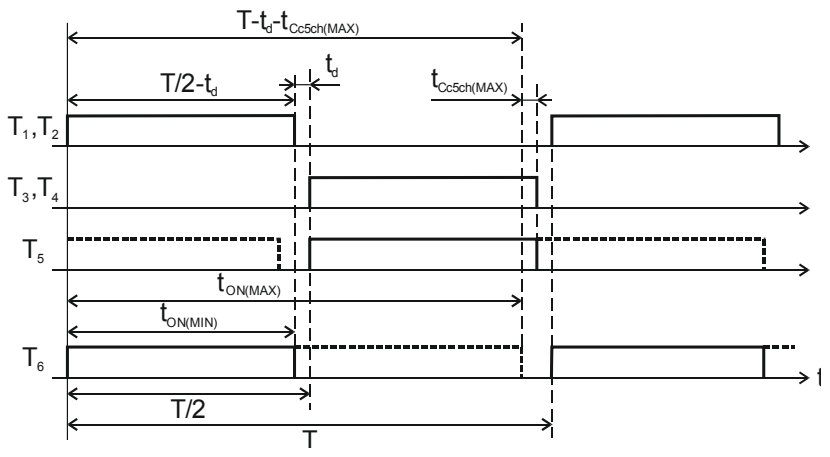

Fig. 4 Control pulses for the converter

Digital signal controller TMS320F28335 was used for controlling the converter. Control circuits have been designed to attain operating conditions similar to those in a conventional electric arc welder. It includes several functions needed to ensure correct welder behaviour under any operating conditions. Two discrete PI regulators $R_{I}$ and $\mathrm{R}_{\mathrm{U}}$ ensure controlling of output voltage $U_{O}$ and smoothing inductor current $I_{L O}$ and thus also output current of the welder $I_{O}$. The PI regulators are connected in parallel (Fig. 5). The control logic selects the regulator with a smaller regulating variable (shorter pulse width).

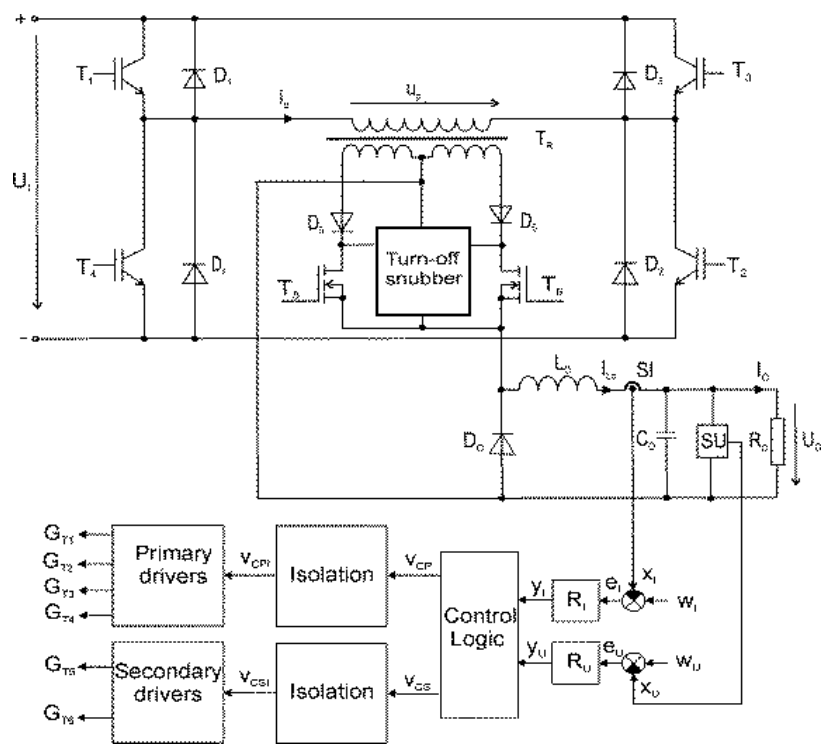

Fig. 5 Block diagram of control structure

The block diagram of discrete PI regulator with limiter is shown in Fig. 6.

The equation that expresses the output parameter of regulator in step $\mathrm{k}$ is:

$y(k)=\left(K+\frac{T}{T_{I}}\right) e(k)-K e(k-1)+y(k-1)$

By varying the pulse width of the secondary transistors, the conduction time of transistors is accordingly increased or decreased and thus regulated is the output current.

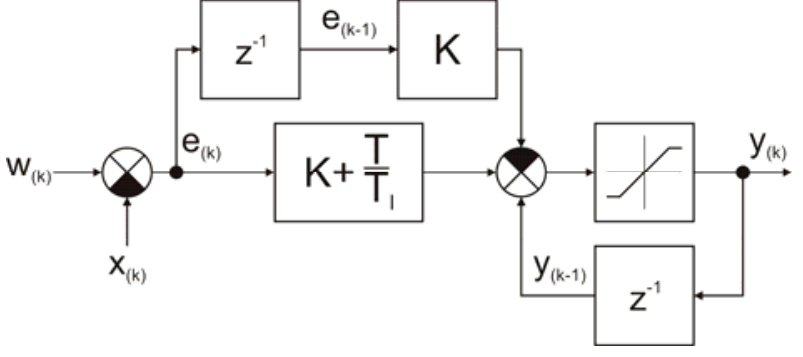

Fig. 6 Discrete PI regulator

The control circuits are completely isolated from power circuits. Arrangement of the basic control board is displayed in Fig. 7.

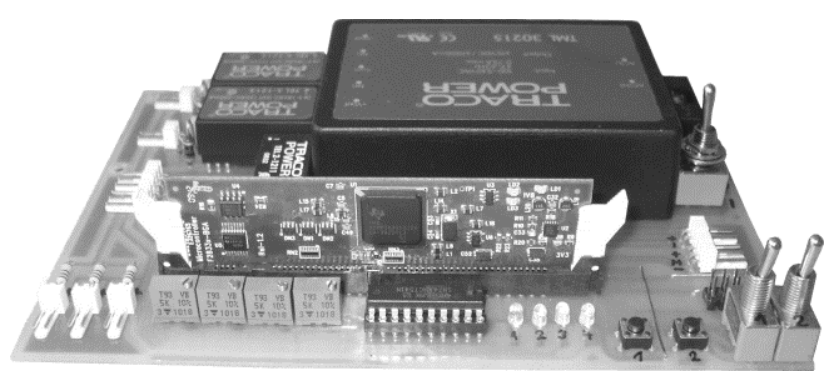

Fig. 7 Basic control board with TMDSCNCD28335 card

\section{EXPERIMENTAL RESULTS}

After verification in simulation program OrCAD, function of the PWM DC-DC converter as a current source used for arc welding application was verified on a laboratory model shown in Fig. 8.

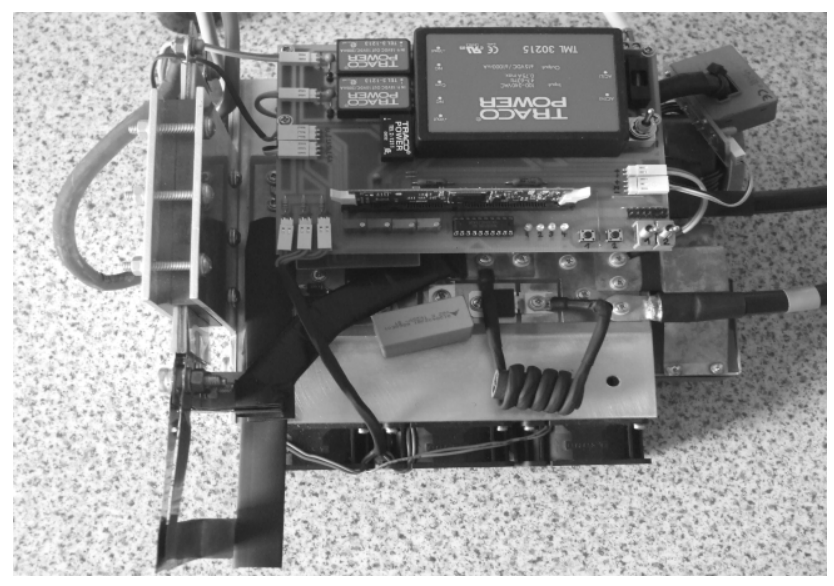

Fig. 8 Laboratory model of the converter

The turn-off snubber described in the previous section was implemented using the components outlined in Table 1.

Table 1 Snubber components

\begin{tabular}{|l|l|}
\hline $\mathrm{L}_{\mathrm{S} 5}, \mathrm{~L}_{\mathrm{S} 6}$ & $0.3 \mu \mathrm{H}$ \\
\hline $\mathrm{C}_{\mathrm{S} 5}, \mathrm{C}_{\mathrm{S} 6}$ & $220 \mathrm{nF}$ \\
\hline $\mathrm{L}_{\mathrm{O}}$ & $5.3 \mu \mathrm{H}$ \\
\hline $\mathrm{C}_{\mathrm{O}}$ & $0.47 \mu \mathrm{F}$ \\
\hline
\end{tabular}


In the inverter, four ultra-fast IGBTs were used. Special high-frequency planar transformer with a very low value of leakage inductance was designed and made using EI ferrite cores. The transformer parameters are shown in Table 2.

Table 2 Planar transformer parameters

\begin{tabular}{|l|l|}
\hline Core & $2 \times E 64$ \\
\hline Material & $3 C 90$ \\
\hline Turn's ratio $\mathrm{n}=\mathrm{n}_{\mathrm{p}} / \mathrm{n}_{\mathrm{s}} / \mathrm{n}_{\mathrm{s}}$ & $5: 1: 1$ \\
\hline Primary winding resistance $\mathrm{R}_{1}$ & $6.5 \mathrm{~m} \Omega$ \\
\hline Secondary winding resistance $\mathrm{R}_{2}$ & $0.75 \mathrm{~m} \Omega$ \\
\hline Magnetizing inductance $\mathrm{L}_{1 \mathrm{H}}$ & $706 \mu \mathrm{H}$ \\
\hline $\begin{array}{l}\text { Leakage inductance referred } \\
\text { to primary side } \mathrm{L}_{\sigma}\end{array}$ & $625 \mathrm{nH}$ \\
\hline Weight & $0.52 \mathrm{~kg}$ \\
\hline
\end{tabular}

Arrangement of the high-frequency power planar transformer is shown in Fig. 9.

Foil windings of the power planar transformer are interleaved, and the primary is sandwiched closely between a split secondary winding in order to achieve tight coupling and thus very low leakage inductance.

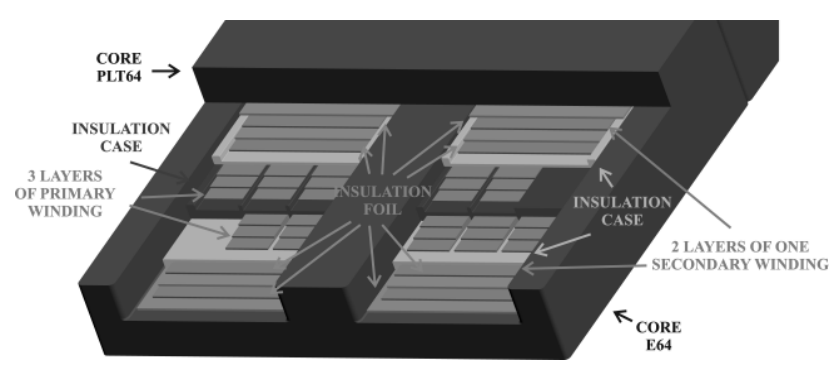

Fig. 9 Power planar transformer arrangement

In output rectifier, ultrafast soft recovery diodes were used. Inductance of the smoothing choke for smoothing of the output rectified current is $L_{S}=5 \mu \mathrm{H}$ only as a result of output rectified voltage frequency of $200 \mathrm{kHz}$. In practical applications this value of smoothing inductance can be partially achieved by utilizing parasitic inductances of the connecting wires.

The measurements were made at nominal input voltage of $U_{I}=325 \mathrm{~V}$.

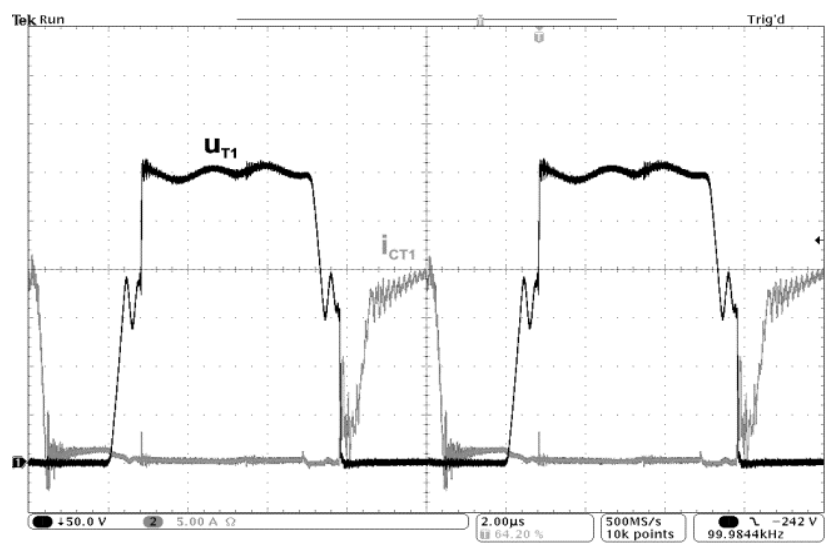

Fig. 10 Collector-emitter voltage $\mathrm{u}_{\mathrm{T} 1}$ and collector current $\mathrm{i}_{\mathrm{CT} 1}$ of primary transistor $T_{1}$
Properties of this laboratory model of the converter working as a current source were verified for output currents of up to 120 Amps.

The voltage and current of primary switch $T_{1}$ are shown in Fig. 10. Transistor $T_{1}$ turns on under zero voltage and zero current. Only small magnetizing current is turned off and thus nearly zero current turn off is achieved. Because of the inverter symmetry, the waveforms for all primary switches $T_{1}-T_{4}$ are identical.

Drain-source voltage and drain current of the secondary MOSFET transistor $T_{5},\left(T_{6}\right)$ at turn-on and turn off are shown in Fig. 11.

Rate of rise of the drain-source voltage $\mathrm{u}_{\mathrm{T} 5}$ at turn off is limited by snubber capacitor $C_{C 5}$ and thus zero voltage turn off of the secondary transistor is achieved.

At the turn on of transistor $T_{5}$, capacitor $C_{C 5}$ is discharged through transistor and snubber inductance $L_{S 5}$ to the load in a resonant way. Therefore the rate of rise of the discharging current is limited and zero current turn on is reached.

Some waveforms at light load are shown in Fig. 12. At low load current, snubber capacitor $C_{C 5}$ is discharged in two intervals as it is seen in Fig. 12. This fact has no influence on the soft switching and output parameters of the converter.

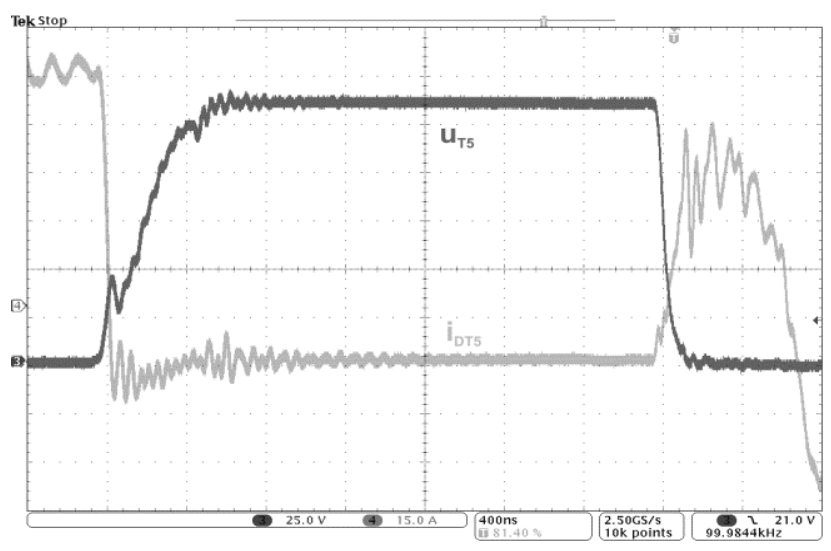

Fig. 11 Drain-source voltage $u_{\mathrm{T} 5}$ and drain current $i_{\mathrm{DT} 5}$ of secondary transistor $\mathrm{T}_{5}$

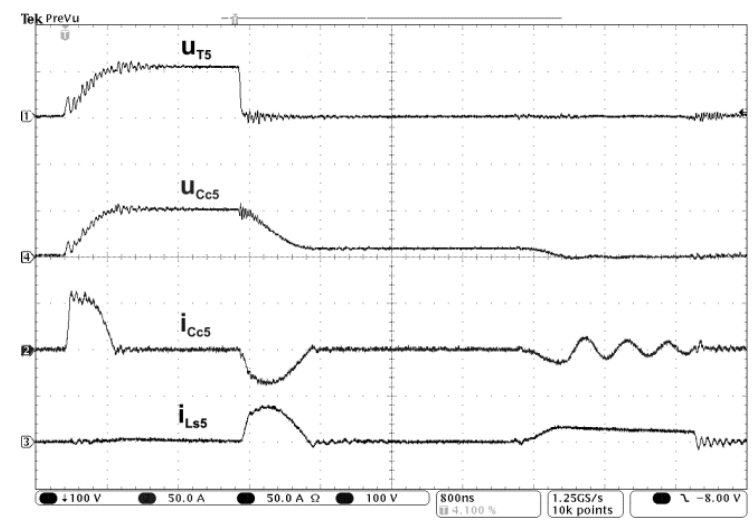

Fig. 12 Drain-source voltage $u_{T 5}$, snubber capacitor voltage $u_{\mathrm{Cc} 5}$ and current $\mathrm{i}_{\mathrm{Cc} 5}$ and snubber inductor current $\mathrm{i}_{\mathrm{Ls} 5}$ at light load

Fig. 13 illustrates output voltage and output current during welding process. 
At no-load the pulse width is pushed by control circuits to the maximum value and no-load output voltage achieves value of some $70 \mathrm{~V}$. When the electrode touches the work piece, the output current is increased rapidly to its predetermined value, while the load voltage drops to zero. During the following welding process the average arc voltage is approximately $24 \mathrm{~V}$ at welding current of about 90A. When the distance between electrode and work piece rises, the arc voltage is increased and consequently the output current falls to zero. Afterwards the output voltage returns to the no-load value.

The welder has very high dynamic properties. Response to the current and voltage fluctuations is very fast due to used high frequency of $200 \mathrm{kHz}$ at the rectifier output (voltage $u_{d}$ in Fig. 1).

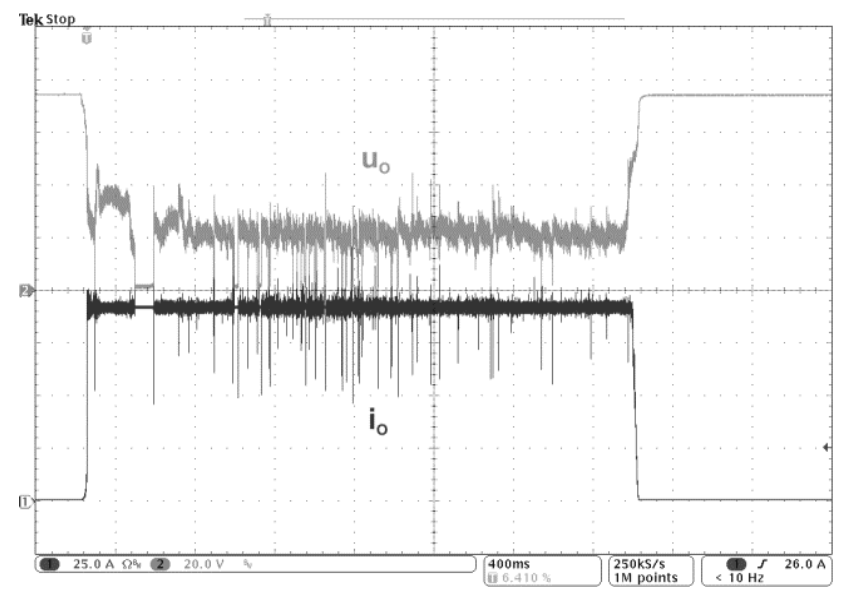

Fig. 13 Output voltage $u_{O}$ and output current $i_{O}$ during welding at output current of $90 \mathrm{~A}$

Measured output characteristics of the DC-DC converter connecting to the rectified voltage of the singlephase grid are shown in Fig. 14. It can be seen that arc welder behaves as a current source in arc voltage range that is approximately from 20 to $30 \mathrm{~V}$.

The efficiency was measured at conditions nearly similar to those at welding process - at output voltage of 25 volts (Fig. 15). The efficiency is approximately $90 \%$.

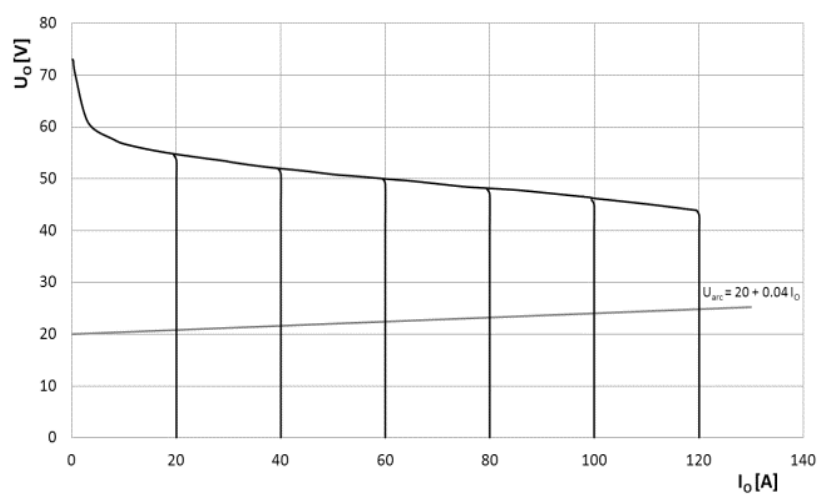

Fig. 14 Measured output characteristics of the welder
Measurement was also performed for $45 \mathrm{~V}$ output only for comparison with other ZVZCS systems. The efficiency is about $94 \%$ under such conditions. This is quite a high value for a converter with low output voltage a high output current.

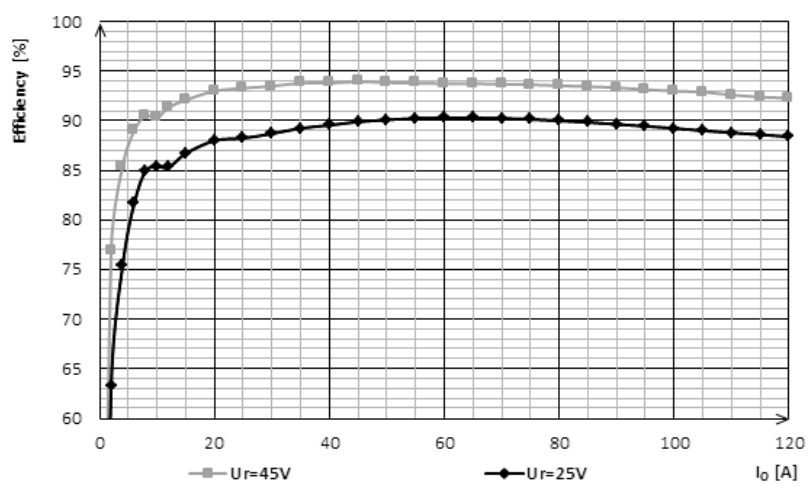

Fig. 15 Measured efficiency of the converter

\section{CONCLUSION}

Welding applications call for dc current sources with small weight and size, good efficiency and acceptable price. One of the options is to build the welders using high frequency soft switching DC-DC converter, which has been discussed in this paper.

The converter presented in this paper has very good behaviour for wide range of the output current.

Soft switching is achieved for all power switches of the converter. Especially primary IGBT transistors operate at almost ideal switching conditions - at zero-voltage and zero-current turn-on and zero-current turn-off.

The certain disadvantage of this topology is the fact that additional switches in series with output rectifier add supplemental conduction losses in the controlled rectifier. In spite of this fact, the controlled rectifier has important, hardly changeable function. As a result of the used active rectifier, the circulating currents in primary switches and power transformer are totally suppressed and thus conduction losses in these devices are considerably reduced. Moreover, by using of the active rectifier the turn-off losses of the primary switches are also substantially decreased.

In addition, main parasitics of the power transformer are integrated into the converter topology.

The non-dissipative snubber consists of passive components only. It is very small a so is additional cost.

Experimental tests on the laboratory model demonstrated feasibility of the proposed converter at operating as a current source e.g. for arc welding applications.

\section{ACKNOWLEDGMENTS}

This work was supported by Scientific Grant Agency of the Ministry of Education of Slovak Republic under the contract VEGA No. 1/0464/15.

The work was supported by FEI-2015-3. 


\section{REFERENCES}

[1] JEON, S. J. - CHO, G. H.: A Zero-Voltage and Zero Current Switching Full Bridge DC-DC Converter with Transformer Isolation, IEEE Trans. on Power Electronics, Vol.16, No.5, pp. 573 - 580, 2001.

[2] WANG, J. M. - WU, S. T. - YEN, S. C. - CHIU, H. J.: A Simple Inverter for Arc-Welding Machines With Current Doubler Rectifier, IEEE Transactions on Industrial Electronics, Vol. 58, No. 11, pp. 5278 -5281, November 2011.

[3] YANG, R. - DING, H. - XU, Y. - YAO, L. XIANG, Y.: An Analytical Steady-State Model of LCC type Series-Parallel Resonant Converter With Capacitive Output Filter, Power Electronics, IEEE Transactions on Vol. 29 , No. 1, pp. 328 - 338, 2014.

[4] FERREIRA, C. A. F. - BORGES, B. V.: Sine-Wave Amplitude-Modulation Concept for Linear Behavior of Phase-Modulated Resonant Converters, Industrial Electronics, IEEE Transactions on, Volume: 60, Issue: 5 pp. 2074 - 2083, 2013.

[5] SARNAGO, H. - LUCIA, O. - MEDIANO, A. BURDIO, J. M.: Design and Implementation of a High-Efficiency Multiple-Output Resonant Converter for Induction Heating Applications Featuring Wide Bandgap Devices Power Electronics, IEEE Transactions on Vol. 29 , No 5, pp. $2539-2549,2014$.

[6] WANG, Y. - XU, D. - WANG, W. - ZHANG, X. XU, B.: Electronic Ballast for Metal Halide Lamps Using a Quasi-Resonant Inverter With Digital Control, Industrial Electronics, IEEE Transactions on, Vol. 59, No. 4, pp. 1825 - 1840, 2012.

[7] CHUDJUARJEEN, S. - HATHAIRATSIRI, V. PECHPUNSRI, W. - SANGSWANG, A. KOOMPAI, C.: Quasi-resonant converter for induction heating in high temperature applications, Power Electronics and Drive Systems (PEDS), 2013 IEEE 10th International Conference on, 2013, pp. $836-839$.

[8] MISHIMA, T. - MIZUTANI, H. - NAKAOKA, M.: Experimental evaluations of a five-element multiresonant DC-DC converter with an improved PFM control range, Power Electronics and Drive Systems (PEDS), 2013 IEEE 10th International Conference on, 2013 , pp. $147-152$.

[9] MUSAVI, F. - CRACIUN, M. - EDINGTON, M. EBERLE, W. - DUNFORD, W. G.: Practical design considerations for a LLC multi-resonant DC-DC converter in battery charging applications in Applied Power Electronics Conference and Exposition (APEC), 2012 Twenty-Seventh Annual IEEE , 2012, pp. $2596-2602$.

[10] GU, B. - LIN, Ch.-Y. - CHEN, B. F. - DOMINIC, J. et al.: Zero-Voltage-Switching PWM Resonant FullBridge Converter With Minimized Circulating
Losses and Minimal Voltage Stresses of Bridge Rectifiers for Electric Vehicle Battery Chargers, IEEE Transactions on Power Electronics, Vol. 28, No. 10 (2013), pp. 4657-4667.

[11] NARIMANI, M. - MOSCHOPOULOS, G.: A New DC/DC Converter With Wide-Range ZVS and Reduced Circulating Current, in IEEE Transactions on Power Electronics, Vol. 28, No. 3 (2013), pp. 1265-1273.

[12] LEE, I.-O. - MOON, G.-W.: Phase-Shifted PWM Converter With a Wide ZVS Range and Reduced Circulating Current, in IEEE Transactions on Power Electronics, Vol. 28, No. 2 (2013), pp. 908-919.

[13] MISHIMA, T. - AKAMATSU, K. - NAKAOKA, M.: A Zero Voltage and Zero Current Soft Switching PWM DC-DC Converter with Secondary-side Phaseshifting Active Rectifier, in Energy Conversion Congress and Exposition (ECCE), 2012, pp. 24552511.

[14] MISHIMA, T. - NAKAOKA, M.: Practical Evaluations of a ZVS-PWM DC-DC Converter with Secondary-Side Phase-Shifting Active Rectifier, IEEE Transactions on Power Electronics, Vol. 26, No. 12 (2011), pp. 3896-3907.

[15] MOISSEEV, S. - SOSHIN, K. - SATO, S. GAMAGE, L. - NAKAOKA, M.: Novel SoftCommutation DC-DC Power Converter With HighFrequency Transformer Secondary Side PhaseShifted PWM Active Rectifier, in IEE Proceedings Electric Power Applications, Vol. 151, Issue 3, 2004, pp. $260-267$.

[16] MISHIMA, T. - AKAMATSU, K. - NAKAOKA, M.: A High Frequency-Link Secondary-Side PhaseShifted Full-Range Soft-Switching PWM DC-DC Converter With ZCS Active Rectifier For EV Battery Chargers, Power Electronics, IEEE Transactions on, Vol. 28, Issue 12, 2013, pp. 5758 5773.

[17] DUDRIK, J. - RUSCIN, V. - BODOR, M.: NonDissipative Turn-Off Snubber for DC-DC Converter with Controlled Output Rectifier, Slovak patent No. 287977, June 2012.

[18] DUDRIK, J. - BODOR, M.: Novel Soft Switching DCDC Converter with Controlled Output Rectifier, In: EPE-PEMC 2012 ECCE Europe: 15th International Power Electronics and Motion Control Conference and Exposition, September 4-6, 2012, Novi Sad, Serbia, 2012, P. DS1b.13-1 - DS1b.13-5.

[19] DUDRIK, J. - BODOR, M. - PÁSTOR, M.: Soft Switching Full - Bridge PWM DC - DC Converter with Controlled Output Rectifier and Secondary Energy Recovery Turn - Off Snubber. In: IEEE Transactions on Power Electronics. Vol. 29, No. 8, 2014, pp. 4116-4125.

Received May 30, 2016, accepted June 30, 2016 


\section{BIOGRAPHIES}

Jaroslav Dudrik received the M.S. and Ph.D. degrees in electrical engineering from the Technical University of Košice, Slovakia, in 1976 and 1987, respectively. He is currently full professor of Electrical Engineering at the Department of Electrical Engineering and Mechatronics, Technical University of Košice, where he is engaged in teaching and research. His primary interest is power electronics. His field of research includes dc-to-dc converters, high power soft switching converters, converters for renewable energy sources and control theory of converters.

Marek Pástor was born in Košice (Slovakia) in 1985. He received his master degree in electrical engineering in 2010 and $\mathrm{PhD}$. in 2014 from Technical University of Košice, Slovakia. He is currently an assistant professor at Dept. of Electrical Engineering and Mechatronics, Faculty of Electrical Engineering and Informatics, Technical
University of Košice, Slovakia. His interest is in the area of power electronics.

Milan Lacko received the M.S. degree and Ph.D. degree in electrical engineering from the Technical University of Košice, Slovakia, in 2005 and 2010. He is currently an assistant professor at Dept. of Electrical Engineering and Mechatronics, Technical University of Košice. His research interests include power electronics, converters and micro-controllers.

Róbert Žatkovič was born in Košice, Slovakia, in 1990. $\mathrm{He}$ received the M.Sc. degree in electrical engineering from the Technical University of Košice, Slovakia, in 2014. He is currently a full-time Ph.D. student at the Department of Electrical Engineering and Mechatronics, Technical University of Košice, Slovakia. His primary interest is power electronics. His field of research includes high frequency DC/DC converters and soft switching techniques. 